\title{
Pharmacokinetics of mycophenolate sodium co-administered with tacrolimus in the first year after renal transplantation
}

\author{
Joanna Sobiak • Matylda Resztak • Maciej Głyda • \\ Paulina Szczepaniak $\cdot$ Maria Chrzanowska
}

Received: 27 October 2014/ Accepted: 28 January 2015/Published online: 7 February 2015

(C) The Author(s) 2015. This article is published with open access at Springerlink.com

\begin{abstract}
We assessed the relations between MPA, free MPA (fMPA) and MPA glucuronide (MPAG) pharmacokinetics and the clinical condition of renal transplant recipients treated with EC-MPS and tacrolimus (Tac) in the first post-transplant year. In 18 adult patients blood samples were collected up to $12 \mathrm{~h}$ after EC-MPS oral administration. EC-MPS metabolites' plasma concentrations were determined using validated HPLC methods. All patients reached MPA area under the time-concentration curve $\left(\mathrm{AUC}_{0-12}\right)$ above $30 \mu \mathrm{g} \mathrm{h} / \mathrm{mL}$. Most of the MPA, fMPA and all MPAG concentrations correlated significantly with respective $\mathrm{AUC}_{0-12}$ values. Some fMPA and all MPAG pharmacokinetic parameters correlated negatively with creatinine clearance and positively with creatinine concentration, whereas no such correlation was observed for MPA. Lower hemoglobin concentrations were observed in patients with higher MPA or fMPA $C_{0}$. The significant correlations between MPA $C_{3}$ as well as MPA $C_{4}$ and MPA $\mathrm{AUC}_{0-4}$ and MPA $\mathrm{AUC}_{0-12}$ may be of importance in further studies including larger number of patients in regard to establishing LSS. In patients treated with EC-MPS and Tac, monitoring MPA $C_{0}$ may be important, as too high MPA $C_{0}$ may contribute to anemia onset. In EC-MPS treated patients, MPAG concentration is related to renal function as MPAG pharmacokinetics were higher in patients with renal impairment.
\end{abstract}

J. Sobiak $(\bowtie) \cdot$ M. Resztak · P. Szczepaniak · M. Chrzanowska Department of Physical Pharmacy and Pharmacokinetics, Poznan University of Medical Sciences, 6 Święcickiego Street, 60-781 Poznań, Poland

e-mail: jsobiak@ump.edu.pl

M. Głyda

Department of Transplantology and General Surgery, Poznań District Hospital, 7/19 Juraszów Street, 60-479 Poznań, Poland
Keywords Enteric-coated mycophenolate sodium • Pharmacokinetics · Mycophenolic acid · Mycophenolate glucuronide $\cdot$ Tacrolimus $\cdot$ Renal transplantation

\section{Introduction}

The enteric-coated formulation of mycophenolate sodium (EC-MPS, Myfortic ${ }^{\circledR}$, Novartis Pharma AG, Basel, Switzerland), used in the prophylaxis of organ rejection, was developed to reduce the incidence of adverse gastrointestinal effects of its active compound, mycophenolic acid (MPA) (Budde et al. 2010; Sánchez Fructuoso et al. 2012). EC-MPS has similar safety profile and adverse gastrointestinal effects incidence (Salvadori et al. 2004; Budde et al. 2007b) to mycophenolate mofetil (MMF, CellCept ${ }^{\circledR}$, Roche AG, Basel, Switzerland). EC-MPS is still most often administrated basing on fixed doses, without monitoring MPA concentrations although MPA is characterized by high protein binding (97-99\%) (Chen et al. 2010) as well as high intra- and interpatient variability of its pharmacokinetics and pharmacodynamics (Budde et al. 2010; Sánchez Fructuoso et al. 2012). The EC-MPS therapy is most often controlled only by assessing patient's clinical condition, although there are some data indicating the efficacy-exposure relationship. In some studies, the correlation between small drug concentration and the risk of acute rejection or between high drug concentration and adverse effects intensity (Budde et al. 2007b, 2010; Sánchez Fructuoso et al. 2012; Durlik and Rowiński 2012) was observed. The best method for effective and safe immunosuppressive therapy is monitoring the active metabolite plasma concentration (Durlik and Rowiński 2012), especially as MPA pharmacokinetics may be influenced by co-administration of other immunosuppressant agents, albumin concentration 
and renal function as well as the pharmacokinetics may vary depending on the type of organ transplanted (Budde et al. 2010).

Pharmacokinetic parameters of MPA and its inactive metabolite, MPA glucuronide (MPAG), depend on the kind of calcineurin inhibitor [cyclosporine (CsA) or tacrolimus (Tac)] co-administrated. CsA may affect the enterohepatic recirculation of MPAG, leading to MPA AUC decrease, whereas Tac influence on the recirculation is probably lower; therefore, MPA exposure is higher in EC-MPS and Tac-treated patients (Kaplan et al. 2005). According to our knowledge, the influence of CsA on EC-MPS pharmacokinetics is widely described in the literature (Budde et al. 2007b; Sanford and Keating 2008; Budde et al. 2010; Capone et al. 2011; Stracke et al. 2012). Although EC-MPS is also frequently co-administered with Tac, more data need to be evaluated for safe and effective therapy (Budde et al. 2007a; Sánchez Fructuoso et al. 2012; Ju et al. 2012; Lee et al. 2012; Li et al. 2013).

The main difficulty is that the determination of the area under the plasma concentration-time curve from 0 to $12 \mathrm{~h}$ (AUC $\mathrm{A}_{0-12}$ ), which describes best MPA total body exposure, is inconvenient, expensive and difficult to achieve as well as influenced by MPA enterohepatic recirculation. Therefore, there are attempts to determine $C_{0}$ in clinical practice, although poor correlation between MPA $C_{0}$ and $\mathrm{AUC}_{0-12}$ is observed (Budde et al. 2007b; Durlik and Rowiński 2012).

The aim of the study was to investigate the pharmacokinetics of EC-MPS metabolites (MPA, fMPA and MPAG) and the clinical condition of kidney transplant recipients receiving concomitantly Tac and steroids in the first year after transplantation.

\section{Patients and methods}

\subsection{Patients}

The study included 18 patients aged 34-72 years within 1 year after transplantation (14-307 days), receiving ECMPS orally at a daily dose of $1,440 \mathrm{mg}$ (720 mg bid) in combination with Tac and steroids (prednisolone). The inclusion criteria were Tac treatment (Advagraf or Prograf) and appropriate EC-MPS dosage (the same dose twice a day). The exclusion criteria were CsA treatment, EC-MPS given in different dosage schedule than twice a day or at two different doses. The patients' demographics and clinical characteristics are presented in Table 1. The protocol biopsies were not performed. Biopsies were taken in the case of acute rejection suspicion based on clinical symptoms. After receiving the biopsy result (within $24 \mathrm{~h}$ ) definitive diagnosis was made. None of the patients showed biopsy-proven acute rejection.
Table 1 Demographic and clinical data of 18 renal transplant recipients

\begin{tabular}{lcc}
\hline Parameter & Median & Min-Max \\
\hline Gender & Male: 10 ; female: 8 \\
Age (years) & 55 & $34-72$ \\
Post-transplant period (days) & 34 & $14-307$ \\
Tacrolimus dose $(\mathrm{mg} / \mathrm{day})$ & 7 & $5-16$ \\
Creatinine concentration $(\mathrm{mg} / \mathrm{dL})$ & 2.1 & $1.1-7.3$ \\
Creatinine clearance $\left(\mathrm{mL} / \mathrm{min} / 1.73 \mathrm{~m}^{2}\right)$ & 31.9 & $7.3-83.5$ \\
Platelets count $\left(10^{-9} / \mathrm{L}\right)$ & 209 & $67-380$ \\
White blood cells count $\left(10^{-9} / \mathrm{L}\right)$ & 7.9 & $3.2-17.3$ \\
Hemoglobin concentration $(\mathrm{g} / \mathrm{dL})$ & 11.2 & $9.1-16.7$ \\
Alanine aminotransferase $(\mathrm{U} / \mathrm{L})$ & 30 & $7-177$ \\
Aspartate aminotransferase $(\mathrm{U} / \mathrm{L})$ & 19 & $9-43$ \\
\hline
\end{tabular}

The study was approved by the Bioethical Committee at Poznan University of Medical Sciences and is in accordance with the Helsinki Declaration of 1975. Informed consent was obtained from the patients prior to initiating the study.

\subsection{MPA, fMPA and MPAG determination}

Blood samples were collected into EDTA tubes before the morning dose of EC-MPS $\left(C_{0}\right)$, and subsequently at $30 \mathrm{~min}$ $\left(C_{0.5}\right), 1 \mathrm{~h}\left(C_{1}\right), 2 \mathrm{~h}\left(C_{2}\right), 3 \mathrm{~h}\left(C_{3}\right), 4 \mathrm{~h}\left(C_{4}\right), 6 \mathrm{~h}\left(C_{6}\right), 9 \mathrm{~h}$ $\left(C_{9}\right)$ and $12 \mathrm{~h}\left(C_{12}\right)$ after EC-MPS administration. All patients were at the steady state on the day of blood collection.

MPA and MPAG plasma concentrations were determined using the validated HPLC method described elsewhere (Elbarbry and Shoker 2007; Chrzanowska et al. 2011) with minor modification. $200 \mu \mathrm{L}$ of plasma was mixed with $100 \mu \mathrm{L}$ of MPA and MPAG standard solutions for the calibration curve or substituted for $100 \mu \mathrm{L}$ of methanol in the case of patients' plasma samples. Subsequently, $200 \mu \mathrm{L}$ of phenytoin (internal standard) dissolved in $0.1 \mathrm{~mol} / \mathrm{L}$ orthophosphoric acid in acetonitrile was added.

Free MPA (fMPA) was analyzed according to the method described elsewhere (Chen et al. 2010) in all plasma samples. The analytical column used for fMPA determination was Zorbax Eclipse XDB C18 (150 mm × $4.6 \mathrm{~mm}, 5 \mu \mathrm{m}$, Agilent Inc., USA).

\subsection{Pharmacokinetic calculations}

The following pharmacokinetic parameters for MPA, fMPA and MPAG were calculated: $C_{0}, C_{\max }, t_{\max }$ and AUC from 0 to $4 \mathrm{~h}\left(\mathrm{AUC}_{0-4}\right)$ and from 0 to $12 \mathrm{~h}\left(\mathrm{AUC}_{0-12}\right)$ 
using the linear trapezoidal rule. The creatinine clearance $\left(\mathrm{CL}_{\mathrm{cr}}\right)$ was estimated using Chronic Kidney Disease Epidemiology Collaboration equation (Levey et al. 2009). For fMPA, the fraction of fMPA (\%) was also calculated.

\subsection{Statistical analysis}

All statistical tests were performed using Statistica software version 10.0 (StatSoft, Cracow, Poland). Normality was determined by the Shapiro-Wilk test. The correlations of data were tested using Pearson or Spearman correlation analysis for the normally and non-normally distributed data, respectively. A $p$ value lower than 0.05 was considered significant. The results are presented as mean \pm standard deviation (SD). Coefficient of variation (CV) was used to express variability of pharmacokinetic parameters.

\section{Results}

\subsection{Pharmacokinetic parameters of MPA, fMPA and MPAG}

Individual plasma concentrations of MPA, fMPA and MPAG versus time for all patients included in the study are shown on Fig. 1.

The calculated MPA, fMPA and MPAG pharmacokinetic parameters are presented in Table 2. Plasma concentrations of MPA, fMPA and MPAG as well as the pharmacokinetic parameters of EC-MPS metabolites were highly variable. Median MPA $C_{0}$ was $3.1 \mu \mathrm{g} / \mathrm{mL}$ and the highest MPA $C_{0}$ in our study was $10.6 \mu \mathrm{g} / \mathrm{mL}$. $50 \%$ of patients reached MPA $\mathrm{AUC}_{0-12}$ therapeutic range of 30-60 $\mu \mathrm{g} \mathrm{h} / \mathrm{mL}$, whereas for the rest of the patients MPA $\mathrm{AUC}_{0-12}$ was $>60 \mu \mathrm{g} \mathrm{h} / \mathrm{mL}$. For $33 \%$ MPA $\mathrm{AUC}_{0-12}$ value was within $40-60 \mu \mathrm{g} \mathrm{h} / \mathrm{mL}$.

The average percentage of fMPA fraction was $0.90 \pm 0.76 \%$ (median $0.77 \%$, range $0.28-7.29 \%$ ). The median fMPA $\mathrm{AUC}_{0-12}$ was $0.449 \mu \mathrm{g} \mathrm{h} / \mathrm{mL}$. In 11 of 18 patients $(61 \%)$ fMPA AUC $_{0-12}$ was $>0.4 \mu \mathrm{g} \mathrm{h} / \mathrm{mL}$.

Most of the MPA, fMPA and all MPAG concentrations correlated significantly with MPA, fMPA and MPAG $\mathrm{AUC}_{0-12}$ and $\mathrm{AUC}_{0-4}$ as presented in Table 3. MPA $C_{2}$ did not correlate with MPA $\mathrm{AUC}_{0-12}$. Moreover, MPA $C_{0}$ and $C_{0.5}$ did not correlate with MPA $\mathrm{AUC}_{0-4}$.

The median MPAG $\mathrm{AUC}_{0-12}$ was about 20-fold higher than MPA $\mathrm{AUC}_{0-12}$ values.

In our study, there were no differences in MPA, fMPA and MPAG pharmacokinetic parameters between patients $<30$ days after the transplantation and patients $>30$ days after the transplantation (data not shown).

\subsection{Kidney function}

The influence of kidney function on pharmacokinetic parameters was analyzed regarding creatinine clearance $\left(\mathrm{CL}_{\mathrm{cr}}\right)$ and creatinine concentration $\left(C_{\mathrm{cr}}\right)$. MPAG pharmacokinetic parameters $\left(\mathrm{AUC}_{0-4}, \mathrm{AUC}_{0-12}, C_{0}, C_{\text {max }}\right)$ correlated negatively with $\mathrm{CL}_{\mathrm{cr}}$ and positively with $C_{\mathrm{cr}}$, whereas none of the MPA pharmacokinetic parameters correlated with $\mathrm{CL}_{\mathrm{cr}}$ and $C_{\mathrm{cr}}$. $\mathrm{AUC}_{0-12}$ of fMPA correlated positively with $C_{\text {cr }}$ (Table 4).

\subsection{Patient characteristics and complete blood count parameters}

None of the MPA, fMPA and MPAG pharmacokinetic parameters correlated either with patient characteristics (age, weight, post-transplant period and Tac dose; data not shown) or with the results of the complete blood count tests [white blood cell (WBC) and platelet (PLT) count, hemoglobin $(\mathrm{Hb})$ concentration; data not shown] with the exceptions of the negative correlations between $\mathrm{Hb}$ concentration and MPA $C_{0}(r=-0.475 ; p=0.046)$ as well as fMPA $\mathrm{C}_{0}(r=-0.540, p=0.021)$.

\section{Discussion}

The aim of our study was to calculate the pharmacokinetic parameters of MPA, fMPA and MPAG in renal transplant recipients treated with EC-MPS, Tac and steroids within 1 year after the transplantation and to compare the results with the literature data concerning EC-MPS administration with either CsA or Tac. We also assessed the influence of kidney function as well as other clinical factors on ECMPS metabolites pharmacokinetics. Additionally, MPA and MPAG concentrations were correlated with MPA and MPAG $\mathrm{AUC}_{0-12}$ as well as with the abbreviated $\mathrm{AUC}_{0-4}$. The results may contribute to assess limited sampling strategy (LSS), which would be more convenient for patients and may be useful for individualizing drug dosage (Pawinski et al. 2002).

Consistent with the literature data (Budde et al. 2007b; Hummel et al. 2007; Shah et al. 2011; Fleming et al. 2011), plasma concentrations of MPA, fMPA and MPAG in our study were found to range widely. According to the CV values, the pharmacokinetic parameters of EC-MPS metabolites were highly variable as well.

Our results are in accordance with the literature data concerning the influence of calcineurin inhibitors on MPA and MPAG pharmacokinetics. In patients included in our study, MPA pharmacokinetic parameters were higher in comparison to patients receiving EC-MPS in combination 
Fig. 1 Individual plasma concentrations of mycophenolic acid (MPA; a), free MPA (fMPA; b) and mycophenolate glucuronide (MPAG; c) versus time in 18 kidney transplant recipients treated with entericcoated mycophenolate sodium (EC-MPS) and tacrolimus (Tac)

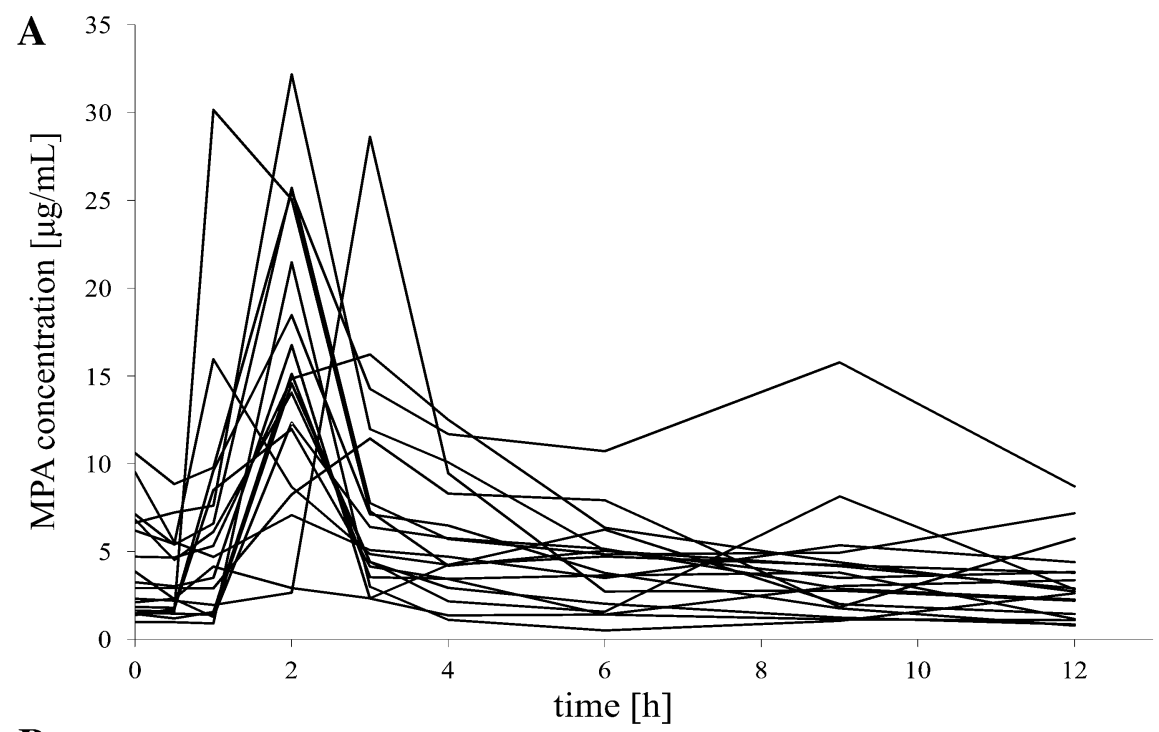

B
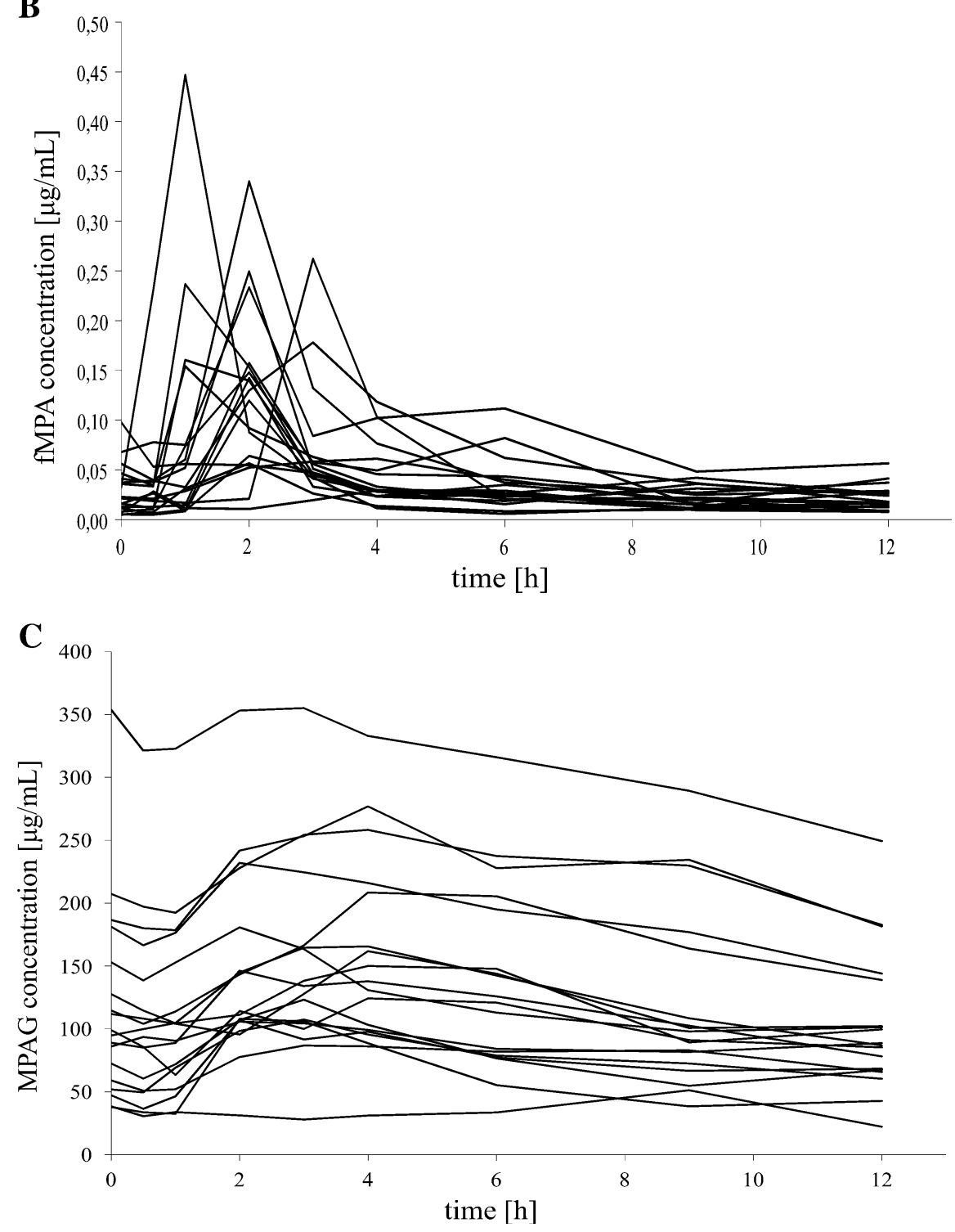
Table 2 The pharmacokinetic parameters of MPA, fMPA and MPAG in renal transplant recipients

\begin{tabular}{|c|c|c|c|c|c|c|c|c|c|}
\hline \multirow[t]{2}{*}{ Parameter } & \multicolumn{3}{|l|}{ MPA } & \multicolumn{3}{|l|}{ fMPA } & \multicolumn{3}{|l|}{ MPAG } \\
\hline & Mean \pm SD & Median & CV (\%) & Mean \pm SD & Median & $\mathrm{CV}(\%)$ & Mean \pm SD & Median & $\mathrm{CV}(\%)$ \\
\hline$C_{0}(\mu \mathrm{g} / \mathrm{mL})$ & $4.2 \pm 3.0$ & 3.1 & 71.6 & $0.030 \pm 0.025$ & 0.022 & 83.4 & $117.3 \pm 78.2$ & 96.9 & 66.7 \\
\hline$C_{\max }(\mu \mathrm{g} / \mathrm{mL})$ & $18.1 \pm 7.5$ & 16.1 & 41.3 & $0.174 \pm 0.107$ & 0.156 & 61.3 & $163.8 \pm 76.8$ & 148.1 & 46.9 \\
\hline$t_{\max }(\mathrm{h})$ & $2.0 \pm 0.6$ & 2.0 & 29.7 & $2.0 \pm 1.0$ & 2.0 & 51.4 & $3.4 \pm 1.6$ & 3.0 & 48.7 \\
\hline $\operatorname{AUC}_{0-12}(\mu \mathrm{g} \mathrm{h} / \mathrm{mL})$ & $67.4 \pm 30.6$ & 61.4 & 45.4 & $0.487 \pm 0.294$ & 0.449 & 60.3 & $1,547.5 \pm 844.7$ & $1,393.2$ & 54.6 \\
\hline $\mathrm{AUC}_{0-4}(\mu \mathrm{g} \mathrm{h} / \mathrm{mL})$ & $34.2 \pm 14.3$ & 28.2 & 41.8 & $0.450 \pm 0.285$ & 0.410 & 63.4 & $577.2 \pm 417.7$ & 472.6 & 72.4 \\
\hline fMPA fraction $(\%)$ & - & - & - & $0.90 \pm 0.76$ & 0.77 & 84.1 & - & - & - \\
\hline
\end{tabular}

Table 3 Correlations between MPA, fMPA and MPAG concentrations and respective $\mathrm{AUC}_{0-4}$ and $\mathrm{AUC}_{0-12}$ in renal transplant recipients

\begin{tabular}{|c|c|c|c|c|c|c|c|c|c|c|c|c|}
\hline \multirow[t]{3}{*}{$C(\mu \mathrm{g} / \mathrm{mL})$} & \multicolumn{4}{|l|}{ MPA } & \multicolumn{4}{|l|}{ fMPA } & \multicolumn{4}{|c|}{ MPAG } \\
\hline & \multicolumn{2}{|c|}{$\operatorname{AUC}_{0-12}(\mu \mathrm{g} \mathrm{h} / \mathrm{mL})$} & \multicolumn{2}{|c|}{$\operatorname{AUC}_{0-4}(\mu \mathrm{g} \mathrm{h} / \mathrm{mL})$} & \multicolumn{2}{|c|}{$\operatorname{AUC}_{0-12}(\mu \mathrm{g} \mathrm{h} / \mathrm{mL})$} & \multicolumn{2}{|c|}{$\mathrm{AUC}_{0-4}(\mu \mathrm{g} \mathrm{h} / \mathrm{mL})$} & \multicolumn{2}{|c|}{$\operatorname{AUC}_{0-12}(\mu \mathrm{g} \mathrm{h} / \mathrm{mL})$} & \multicolumn{2}{|c|}{$\mathrm{AUC}_{0-4}(\mu \mathrm{g} \mathrm{h} / \mathrm{mL})$} \\
\hline & $r$ & $p$ & $r$ & $p$ & $r$ & $p$ & $r$ & $p$ & $r$ & $p$ & $r$ & $p$ \\
\hline$C_{0}$ & 0.560 & 0.016 & 0.404 & 0.097 & 0.732 & 0.001 & 0.752 & $<0.001$ & 0.955 & $<0.001$ & 0.950 & $<0.001$ \\
\hline$C_{0.5}$ & 0.564 & 0.015 & 0.443 & 0.066 & 0.709 & 0.001 & 0.728 & 0.001 & 0.955 & $<0.001$ & 0.955 & $<0.001$ \\
\hline$C_{1}$ & 0.595 & 0.009 & 0.618 & 0.006 & 0.804 & $<0.001$ & 0.796 & $<0.001$ & 0.971 & $<0.001$ & 0.977 & $<0.001$ \\
\hline$C_{2}$ & 0.335 & 0.174 & 0.550 & 0.018 & 0.525 & 0.025 & 0.511 & 0.030 & 0.833 & $<0.001$ & 0.884 & $<0.001$ \\
\hline$C_{3}$ & 0.858 & $<0.001$ & 0.769 & $<0.001$ & 0.503 & 0.034 & 0.496 & 0.036 & 0.942 & $<0.001$ & 0.957 & $<0.001$ \\
\hline$C_{4}$ & 0.759 & $<0.001$ & 0.589 & 0.010 & 0.457 & 0.056 & 0.437 & 0.070 & 0.975 & $<0.001$ & 0.953 & $<0.001$ \\
\hline$C_{6}$ & 0.666 & 0.003 & - & - & 0.313 & 0.206 & - & - & 0.948 & $<0.001$ & - & - \\
\hline$C_{9}$ & 0.639 & 0.004 & - & - & 0.847 & $<0.001$ & - & - & 0.959 & $<0.001$ & - & - \\
\hline$C_{12}$ & 0.666 & 0.003 & - & - & 0.612 & 0.007 & - & - & 0.948 & $<0.001$ & - & - \\
\hline$C_{\max }$ & 0.517 & 0.028 & 0.781 & $<0.001$ & 0.872 & $<0.001$ & 0.874 & $<0.001$ & 0.959 & $<0.001$ & 0.953 & $<0.001$ \\
\hline
\end{tabular}

Table 4 Correlations between MPA, fMPA and MPAG pharmacokinetic parameters and renal function in renal transplant recipients

* Pearson correlation analysis

\begin{tabular}{|c|c|c|c|c|c|c|}
\hline & \multicolumn{2}{|l|}{ MPA } & \multicolumn{2}{|l|}{ fMPA } & \multicolumn{2}{|l|}{ MPAG } \\
\hline & $r$ & $p$ & $r$ & $p$ & $r$ & $p$ \\
\hline \multicolumn{7}{|c|}{ Creatinine clearance $(\mathrm{mL} / \mathrm{min})$} \\
\hline $\mathrm{AUC}_{0-4}(\mu \mathrm{g} \mathrm{h} / \mathrm{mL})$ & -0.024 & 0.926 & -0.373 & 0.128 & -0.690 & 0.002 \\
\hline $\operatorname{AUC}_{0-12}(\mu \mathrm{g} \mathrm{h} / \mathrm{mL})$ & 0.063 & 0.804 & -0.414 & 0.088 & -0.657 & 0.003 \\
\hline$C_{0}(\mu \mathrm{g} / \mathrm{mL})$ & -0.191 & 0.448 & -0.356 & 0.147 & -0.697 & 0.001 \\
\hline$C_{\max }(\mu \mathrm{g} / \mathrm{mL})$ & $0.168 *$ & 0.505 & $-0.207 *$ & 0.409 & $-0.630^{*}$ & 0.005 \\
\hline \multicolumn{7}{|c|}{ Creatinine concentration $(\mathrm{mg} / \mathrm{dL})$} \\
\hline $\mathrm{AUC}_{0-4}(\mu \mathrm{g} \mathrm{h} / \mathrm{mL})$ & 0.046 & 0.855 & 0.467 & 0.051 & 0.676 & 0.002 \\
\hline $\operatorname{AUC}_{0-12}(\mu \mathrm{g} \mathrm{h} / \mathrm{mL})$ & -0.013 & 0.958 & 0.494 & 0.037 & 0.634 & 0.005 \\
\hline$C_{0}(\mu \mathrm{g} / \mathrm{mL})$ & 0.276 & 0.268 & 0.436 & 0.071 & 0.654 & 0.003 \\
\hline$C_{\max }(\mu \mathrm{g} / \mathrm{mL})$ & -0.031 & 0.903 & 0.372 & 0.129 & 0.605 & 0.008 \\
\hline
\end{tabular}

with CsA (Budde et al. 2007b; Stracke et al. 2012) and comparable to the literature data in Chinese patients receiving EC-MPS and Tac with the exception of shorter MPA $t_{\text {max }}$ in our study (5.0 vs. $2.0 \mathrm{~h}$ ) (Li et al. 2013). MPA $t_{\max }$ in our study was comparable, however, to most of the literature data (1.5-3.5 h) (Budde et al. 2007a; Shah et al. 2011; Tett et al. 2011; Stracke et al. 2012). All MPAG pharmacokinetic parameters in our study were lower than those in patients receiving EC-MPS with CsA (Stracke et al. 2012). The median MPAG $\mathrm{AUC}_{0-12}$ was about 20-fold higher than MPA $\mathrm{AUC}_{0-12}$ values and the result was lower than those in patients receiving EC-MPS in combination with CsA (52-fold higher for MPAG) (Stracke et al. 2012). 
The target recommended MPA $C_{0}$ value is $\geq 1.3$ and $\geq 1.9 \mu \mathrm{g} / \mathrm{mL}$ for renal transplant recipients receiving MMF with CsA and MMF with Tac, respectively (van Gelder et al. 2006). Although it has not been thoroughly investigated, the target MPA $C_{0}$ for MMF may not be applicable for EC-MPS due to two reasons. First, the enteric-coating of EC-MPS delays the occurrence of $C_{\max }$ and second, after EC-MPS administration higher and more variable MPA $C_{0}$ with overall MPA exposure similar to that observed after MMF administration are observed (Budde et al. 2007a, b; Stracke et al. 2012). For MMF and Tac, MPA $C_{0}>3 \mu \mathrm{g} / \mathrm{mL}$ may be related to more common adverse effects (Borrows et al. 2006); however, in our study, 9 of 18 patients $(50 \%)$ had MPA $C_{0}>3 \mu \mathrm{g} / \mathrm{mL}$ and no significant adverse effects were observed. None of the patients in our study reached MPA $C_{0} 15 \mu \mathrm{g} / \mathrm{mL}$, which could be related to very prolonged release of MPA from the evening EC-MPS dose. It is proved that MPA and MPAG exposures increased from week 2 to week 12 post-transplant after prolonged EC-MPS and CsA co-administration (Hummel et al. 2007). In our study, however, probably due to a small number of patients, none of the MPA or MPAG pharmacokinetic parameters correlated with the posttransplant period and we did not observe any differences in the pharmacokinetics between patients who were within 30 days [the early post-transplant period (Stracke et al. 2012)], and those who were more than 30 days after the transplantation. The highest and the lowest MPAG $C_{0}$ were observed 22 and 14 days after the transplantation, respectively. The only patient who was $>6$ months after the transplantation had one of the lowest MPA and MPAG $C_{0}$ values.

The target MPA AUC value, recommended for sufficient immunosuppression in renal transplant recipients receiving $\mathrm{MMF}$ and $\mathrm{CsA}$, especially in the early posttransplant period, is $30-60 \mu \mathrm{g} \mathrm{h} / \mathrm{mL}$ (van Gelder et al. 2006; Sanford and Keating 2008) or 40-60 $\mu \mathrm{g} \mathrm{h} / \mathrm{mL}$ for EC-MPS and CsA therapy (Glander et al. 2010; Stracke et al. 2012). MPA $\mathrm{AUC}_{0-12}$ therapeutic range of $30-60 \mu \mathrm{g} \mathrm{h} / \mathrm{mL}$ was reached in 9 of 18 patients $(50 \%)$ included in our study. The $\mathrm{AUC}_{0-12}$ values in the remaining $50 \%$ of the patients exceeded the upper limit of the therapeutic range $(>60 \mu \mathrm{g} \mathrm{h} / \mathrm{mL})$. Although the toxic range for MPA AUC has not been established, AUC $>60 \mu \mathrm{g} \mathrm{h} /$ $\mathrm{mL}$ may be related to the increased incidence of the adverse events such as leucopenia, thrombocytopenia and gastrointestinal disorders. Some authors also observed high MPA $\mathrm{AUC}_{0-12}$ after EC-MPS and Tac therapy without greater incidence of the adverse effects (Shah et al. 2011; Sánchez Fructuoso et al. 2012). Sumethkul et al. (2005) reported high MPA AUC exposure $(>60 \mu \mathrm{g} \mathrm{h} / \mathrm{mL})$ also after EC-MPS and CsA therapy. The percentage of patients (33\%), who reached MPA $\mathrm{AUC}_{0-12}$ therapeutic range of
40-60 $\mu \mathrm{g} \mathrm{h} / \mathrm{mL}$ in our study, was slightly higher than in the Stracke et al. (25\%) study. Apart from the kind of calcineurin inhibitor administered, higher MPA AUC may be due to a different MPA determination method (enzymemultiplied immunoassay) (Sánchez Fructuoso et al. 2012).

The data concerning the relationship between MPA exposure and the incidence of acute rejection are limited in renal transplant recipients treated with EC-MPS (Le Meur et al. 2011). According to the literature (Budde et al. 2010), patients with biopsy-proven acute rejection showed lower MPA $\mathrm{AUC}_{0-12}(28 \mu \mathrm{g} \mathrm{h} / \mathrm{mL})$ in comparison to the rejection-free patients (MPA $\mathrm{AUC}_{0-12} 40 \mu \mathrm{g} \mathrm{h} / \mathrm{mL}$ ). In our study, we did not observe any acute rejection, probably because MPA $\mathrm{AUC}_{0-12}$ was $>30 \mu \mathrm{g} \mathrm{h} / \mathrm{mL}$ in all patients.

In our study, MPA $C_{0}$ correlation with $\mathrm{AUC}_{0-12}$ was weaker than that in the Budde et al. (2007b) study and stronger than that in the Stracke et al. (2012) study. Poor correlations between $C_{0}$ and total MPA AUC, which may be even weaker for EC-MPS than for MMF, indicate that MPA $C_{0}$ does not reflect systemic exposure to MPA regardless of the kind of calcineurin inhibitor (CsA or Tac) co-administered (Pawinski et al. 2002; Budde et al. 2007b; Neumann et al. 2008; de Winter et al. 2008; Sánchez Fructuoso et al. 2012; Li et al. 2013). In our study, all MPA concentrations (except for $C_{2}$ ) correlated significantly with MPA $\mathrm{AUC}_{0-12}$ as well as with MPA $\mathrm{AUC}_{0-4}$. The most significant correlations were observed for MPA $C_{3}$ and $C_{4}$ similar to or even stronger than those in the literature (Sánchez Fructuoso et al. 2012; Stracke et al. 2012). However, in the case of EC-MPS some authors suggest that the estimation of MPA $\mathrm{AUC}_{0-12}$ based on the plasma concentrations drawn within 2 or $3 \mathrm{~h}$ after dosing is likely to provide conflicting results due to the variability in MPA $t_{\max }$ (Tett et al. 2011). In patients included in our study, MPA $C_{12}$ correlated significantly with $\mathrm{AUC}_{0-12}$ stronger than in the Stracke et al. (2012) study, whereas in Chinese patients treated with EC-MPS and Tac, MPA $C_{7}$ predicted MPA AUC the best (Li et al. 2013).

In therapeutic monitoring, MPA $C_{\max }$ should preferably rather not be used due to its weaker correlation with MPA $\mathrm{AUC}_{0-12}$ and great $t_{\max }$ variability (Budde et al. 2007a; Shah et al. 2011; Tett et al. 2011; Stracke et al. 2012). This is confirmed in our study as the correlation between MPA $C_{\text {max }}$ and MPA $\mathrm{AUC}_{0-12}$ was the second weakest.

All MPAG concentrations correlated significantly with MPAG $\mathrm{AUC}_{0-12}$ and $\mathrm{AUC}_{0-4}$. The best correlations were seen between $C_{1}$ and $C_{4}$ and the weakest in $C_{2}$. According to the literature data, patients treated with EC-MPS in combination with $\mathrm{CsA}, C_{0}, C_{2}, C_{12}$ and $C_{\max }$ correlated well with the MPAG $\mathrm{AUC}_{0-12}$ (Stracke et al. 2012).

Additionally, we observed significant correlations between most of the fMPA concentrations and IMPA $\mathrm{AUC}_{0-12}$ and $\mathrm{AUC}_{0-4}$. This finding may contribute to 
therapeutic monitoring as the determination method of fMPA is fast and easy (Chen et al. 2010). Median fMPA $\mathrm{AUC}_{0-12}$ presented in our study was similar to the literature data $(0.48 \mu \mathrm{g} \mathrm{h} / \mathrm{mL})$ but median fMPA fraction was lower (0.77 vs. $1.65 \%$ ) (Stracke et al. 2012).

Higher values of MPAG pharmacokinetic parameters observed in patients with lower $\mathrm{CL}_{\mathrm{cr}}$ and higher $C_{\mathrm{cr}}$ are in accordance with the literature data. Some authors observed significant negative correlations between glomerular filtration rate and MPAG and fMPA $\mathrm{AUC}_{0-12}$ and lack of correlation for MPA $\mathrm{AUC}_{0-12}$ (Stracke et al. 2012). According to the literature data, high values of MPAG pharmacokinetic parameters result from MPAG accumulation in patients with impaired renal function (Behrend and Braun 2005). We also observed higher fMPA $C_{0}$ in patients with lower $\mathrm{CL}_{\mathrm{cr}}$. Our results showed that in one patient with very high MPA and MPAG concentrations, $C_{\mathrm{cr}}$ amounted to $7.3 \mathrm{mg} / \mathrm{dL}$ and exceeded the reference range by about fivefold. The $\mathrm{CL}_{\mathrm{cr}}$ value for this patient $\left(7.3 \mathrm{~mL} / \mathrm{min} 1.73 \mathrm{~m}^{2}\right)$ indicated end-stage renal insufficiency.

We also analyzed the influence of complete blood count parameters, such as WBC and PLT counts, Hb concentration, as well as other factors (patients' age, Tac dose) on MPA, fMPA and MPAG pharmacokinetic parameters. We found one study, concerning patients receiving EC-MPS and CsA, where neither MPA nor MPAG pharmacokinetics correlated with WBC and PLT counts or with $\mathrm{Hb}$ and albumin concentrations (Stracke et al. 2012). In our study, no significant correlations, except for lower $\mathrm{Hb}$ concentrations in patients with higher MPA $C_{0}$ and fMPA $C_{0}$, were observed. Nevertheless, these correlations indicate the necessity of MPA $C_{0}$ monitoring during EC-MPS and Tac treatment as too high MPA $C_{0}$ may contribute to anemia onset in these patients.

\section{Conclusion}

The significant correlations between MPA $C_{3}$ as well as MPA $C_{4}$ and MPA $\mathrm{AUC}_{0-4}$ and MPA $\mathrm{AUC}_{0-12}$ may be of importance in further studies including larger number of patients in regard to establishing LSS. Similarly as for MMF therapy, in EC-MPS treated patients MPAG concentration is related to renal function as MPAG pharmacokinetics were higher in patients with renal impairment. In patients treated with EC-MPS and Tac, monitoring MPA $C_{0}$ may be important, as too high MPA $C_{0}$ may contribute to anemia onset. However, it should be emphasized that there are some limitations in this study, e.g. the lack of a control group, the cross-sectional design and the small number of patients. This work may serve as a starting point for further and multicenter studies.
Acknowledgments The authors would like to acknowledge Roche Pharmaceuticals (Palo Alto, USA) for kindly supplying mycophenolic acid glucuronide (MPAG) for analytical purposes.

The authors thank Jill Parker for her language assistance.

Open Access This article is distributed under the terms of the Creative Commons Attribution Noncommercial License which permits any noncommercial use, distribution, and reproduction in any medium, provided the original author(s) and the source are credited.

\section{References}

Behrend M, Braun F (2005) Enteric-coated mycophenolate sodium tolerability profile compared with mycophenolate mofetil. Drugs 65:1037-1050

Borrows R, Chusney G, Loucaidou M, James A, Lee J, Tromp JV, Owen J et al (2006) Mycophenolic acid 12-h trough level monitoring in renal transplantation: association with acute rejection and toxicity. Am J Transplant 6:121-128

Budde K, Glander P, Krämer BK, Fischer W, Hoffmann U, Bauer S, Grohmann J et al (2007a) Conversion from mycophenolate mofetil to enteric-coated mycophenolate sodium in maintenance renal transplant recipients receiving tacrolimus: clinical, pharmacokinetic, and pharmacodynamic outcomes. Transplantation $83: 417-424$

Budde K, Tedesco-Silva H, Pestana JM, Glander P, Neumayer HH, Felipe CR, Machado PP et al (2007b) Enteric-coated mycophenolate sodium provides higher mycophenolic acid predose levels compared with mycophenolate mofetil: implications for therapeutic drug monitoring. Ther Drug Monit 29:381-384

Budde K, Dürr M, Liefeldt L, Neumayer HH, Glander P (2010) Enteric-coated mycophenolate sodium. Expert Opin Drug Saf 9:981-994

Capone D, Tarantino G, Kadilli I, Polichetti G, Basile V, Federico S, Sabbatini M (2011) Evalutation of mycophenolic acid systemic exposure by limited sampling strategy in kidney transplant recipients receiving enteric-coated mycophenolate sodium (ECMPS) and cyclosporine. Nephrol Dial Transplant 26:2025-3019

Chen B, Gu Z, Chen H, Zhang W, Fen X, Cai W, Fan Q (2010) Establishment of high-performance liquid chromatography and enzyme multiplied immunoassay technology methods for determination of free mycophenolic acid and its application in Chinese liver transplant recipients. Ther Drug Monit 32:653-660

Chrzanowska M, Kamińska J, Sobiak J, Czarnecka J, Głyda M, Mazurek S (2011) Wstępne badania pojemności antyoksydacyjnej, stężenia niektórych witamin i parametrów farmakokinetycznych mykofenolanu mofetylu u chorych po przeszczepieniu nerki (Polish). Probl Ter Monit 22:31-38

de Winter BC, van Gelder T, Glander P, Cattaneo D, Tedesco-Silva H, Neumann I, Hilbrands L et al (2008) Population pharmacokinetics of mycophenolic acid: a comparison between entericcoated mycophenolate sodium and mycophenolate mofetil in renal transplant recipients. Clin Pharmacokinet 47:827-838

Durlik M, Rowiński W (2012) Zalecenia dotyczące leczenia immunosupresyjnego po przeszczepieniu narządów unaczynionych opracowane przez: Polskie Towarzystwo Transplantacyjne; Konsultanta Krajowego w dziedzinie Transplantologii Klinicznej. Fundacja Zjednoczeni dla Transplantacji, Warsaw (in Polish)

Elbarbry A, Shoker A (2007) Liquid chromatographic determination of mycophenolic acid and its metabolites in human kidney transplant plasma: pharmacokinetic application. J Chromatogr B Analyt Technol Biomed Life Sci 859:276-281 
Fleming DH, Mathew BS, Prasanna S, Annapandian VM, John GT (2011) A possible simplification for the estimation of area under the curve $\left(\mathrm{AUC}_{0-12}\right)$ of enteric-coated mycophenolate sodium in renal transplant patients receiving tacrolimus. Ther Drug Monit 33:165-170

Glander P, Sommerer C, Arns W, Ariatabar T, Kramer S, Vogel EM, Shipkova M et al (2010) Pharmacokinetics and pharmacodynamics of intensified versus standard dosing of mycophenolate sodium in renal transplant patients. Clin J Am Soc Nephrol 5:503-511

Hummel M, Yonan N, Ross H, Miller LW, Sechaud R, Balez S, Koelle EU et al (2007) Pharmacokinetics and variability of mycophenolic acid from enteric-coated mycophenolate sodium compared with mycophenolate mofetil in the novo heart transplant recipients. Clin Transplant 21:18-23

Ju MK, Park SH, Kim SJ, Moon IS, Kim SY (2012) A 6-month, openlabel, multicenter clinical study in Korean de novo renal transplant patients evaluating the efficacy, safety, and tolerance of myfortic concomitantly used with tacrolimus. Transplant Proc 44:144-146

Kaplan B, Meier-Kriesche HU, Minnick P, Bastien MC, Sechaud R, Yeh CM, Balez S et al (2005) Randomized calcineurin inhibitor cross over study to measure the pharmacokinetics of coadministered enteric-coated mycophenolate sodium. Clin Transplant 19:551-558

Le Meur Y, Borrows R, Pescovitz MD, Budde K, Grinyo J, Bloom R, Gaston R et al (2011) Therapeutic drug monitoring of mycophenolates in kidney transplantation: report of The Transplantation Society consensus meeting. Transplant Rev (Orlando) 25:58-64

Lee PC, Chang SS, Shieh SC, Wu ZC, Wang WM, Wang JD, Hung $\mathrm{CJ}$ et al (2012) Cyclosporine or tacrolimus: which is the better partner for myfortic or cell cept? Transplant Proc 44:137-139

Levey AS, Stevens LA, Schmid CH et al (2009) A new equation to estimate glomerular filtration rate. Ann Intern Med 150:604-612

Li J, Liu Y, Huang J, Fu Q, Chen E, Liu L, Zhang R et al (2013) Evaluation of mycophenolic acid exposure using a limited sampling strategy in renal transplant recipients. Am J Nephrol 37:534-540

Neumann I, Fuhrmann H, Kanzler M, Fang IF, Jaeger A, Graf H, Bayer P et al (2008) Pharmacokinetics of enteric-coated mycophenolate sodium: comparative study in patients with autoimmune disease and renal allograft. Expert Opin Pharmacother 9:879-886
Pawinski T, Hale M, Korecka M, Fitzsimmons WE, Shaw LM (2002) Limited sampling strategy for the estimation of mycophenolic acid area under the curve in adult renal transplant patients treated with concomitant tacrolimus. Clin Chem 48:1497-1504

Salvadori M, Holzer H, de Mattos A, Sollinger H, Arns W, Oppenheimer F, Maca J et al (2004) Enteric-coated mycophenolate sodium is therapeutically equivalent to mycophenolate mofetil in de novo renal transplant patients. Am J Transplant 4:231-236

Sánchez Fructuoso AI, Perez-Flores I, Calvo N, Valero R, Matilla E, Ortega D, Del Dedo MA et al (2012) Limited-sampling strategy for mycophenolic acid in renal transplant recipients receiving enteric-coated mycophenolate sodium and tacrolimus. Ther Drug Monit 34:298-305

Sanford M, Keating GM (2008) Enteric-coated mycophenolate sodium a review of its use in the prevention of renal transplant rejection. Drugs 68:2505-2533

Shah T, Tellez-Corrales E, Yang JW, Qazi Y, Wang J, Wilson J, Hutchinson I et al (2011) The pharmacokinetics of entericcoated mycophenolate sodium and its gastrointestinal side effects in de novo renal transplant recipients of Hispanic ethnicity. Ther Drug Monit 33:45-49

Stracke S, Shipkova M, Mayer J, Keller F, Zarghom A, Yang L, Henne-Bruns D et al (2012) Pharmacokinetics and pharmacodynamics of mycophenolate sodium (EC-MPS) co-administered with cyclosporine in the early-phase post-kidney transplantation. Clin Transplant 26:57-66

Sumethkul V, Na-Bangchang K, Kantachuvesiri S, Jirasiritham S (2005) Standard dose enteric-coated mycophenolate sodium (myfortic) delivers rapid therapeutic mycophenolic acid exposure in kidney transplant recipients. Transplant Proc 37:861-863

Tett SE, Saint-Marcoux F, Staatz CE, Brunet M, Vinks AA, Miura M, Marquet $\mathrm{P}$ et al (2011) Mycophenolate, clinical pharmacokinetics, formulations, and methods for assessing drug exposure. Transplant Rev (Orlando) 25:47-57

van Gelder T, Le Meur Y, Shaw LM, Oellerich M, De Nofrio D, Holt C, Holt DW et al (2006) Therapeutic drug monitoring of mycophenolate mofetil in transplantation. Ther Drug Monit 28:145-154 